\title{
Efecto de la suplementación con grasa protegida sobre la producción y calidad de carne de toretes mexicanos doble propósito
}

\section{Effect of supplementing with protected fat on meat production and quality of mexican dual purpose steers}

\author{
Juan Reyes D, ${ }^{1}$ M.Sc, Omar Hernández M, ${ }^{*}$ Ph.D, Efrén Ramírez $B,{ }^{1}$ Ph.D, \\ Isabel Guerrero L, ${ }^{2}$ Ph.D, Gilberto Aranda O, ${ }^{3}$ Ph.D, German Mendoza M, ${ }^{4}$ Ph.D.
}

${ }^{1}$ Colegio de Postgraduados, Ganadería. Montecillo. Texcoco. 56230. México. ${ }^{2}$ Universidad Autónoma Metropolitana-I. Iztapalapa. México D.F. 55535. México. ${ }^{3}$ Universidad Autónoma Chapingo. Departamento de Zootecnia. Chapingo, Mexico. 56230. México. ${ }^{4}$ Universidad Autónoma Metropolitana-X. Coyoacán. México. D.F. 04960. México. *Correspondencia: ohmendo@colpos.mx

Recibido: Junio de 2009; Aceptado: Marzo de 2010.

\section{RESUMEN}

Objetivo. Evaluar la respuesta productiva y calidad de la carne de toretes doble propósito a la adición de grasa protegida (GP) en su dieta. Materiales y métodos. Se utilizaron 45 toretes comerciales ( $B$. taurus $\times$ B . indicus), divididos en tres bloques de 15 animales, de acuerdo con su peso vivo en pequeños, medianos y grandes. Cada bloque fue dividido en tres subgrupos de 5 animales, asignados aleatoriamente a los tratamientos $0,1.5$ y $3 \%$ de GP, en un diseño de bloques completamente al azar. Resultados. No hubo diferencias $(p>0.05)$ en comportamiento productivo. La grasa dorsal fue mayor $(p<0.05)$ en animales alimentados con 0\% GP comparado con 3\% de GP (9.6 vs $8.6 \mathrm{~mm}$ ). No hubo diferencias $(p>0.05)$ en área del ojo de la costilla $(A C)$ ni pH de la carne. El contenido de proteína cruda de la carne incrementó $(p<0.05)$ con $3 \%$ GP pero disminuyó $(p<0.05)$ con 1.5 y $0 \%$ de GP (22.8 vs $21.6,21.6$, respectivamente). El perfil de ácidos grasos no fue diferente $(p>0.05)$ entre tratamientos. Conclusiones. Adicionar GP a dietas para bovinos doble propósito en finalización no modificó la respuesta productiva, pero mejoró algunas características de la canal y de la carne. Se sugiere realizar más investigación, utilizando el mismo tipo de animales, con niveles mayores de GP a los usados en este estudio, ya que la respuesta pudiera mejorar.

Palabras clave: Carne, ganadería, alimentación animal, control de calidad, México. (Fuente: DeCS) 


\section{ABSTRACT}

Objective. To evaluate performance and meat quality response to protected fat (PF) addition to diets for dual purpose steers. Materials and methods. Forty five commercial crossed steers ( $B$. taurus $\times$ B . indicus) were used. They were allocated into three blocks of 15 animals, according to live-weight into small, medium and large steers. Each block was divided into three groups of 5 animals, and then assigned at random to three treatments: $0,1.5$ and $3 \%$ of PF, within a completely randomized block design. Results. There were not differences $(p>0.05)$ on animal performance. Backfat was greater $(p<0.05)$ on animals fed at $0 \%$ PF compared to $3 \%$ of GP (9.6 vs $8.6 \mathrm{~mm})$. There were not differences $(p>0.05)$ on Longissimus muscle area (LMA) nor on $\mathrm{pH}$. Meat crude protein increased $(p<0.05)$ on animals fed at $3 \%$ of PF, but it decreased $(p<0.05)$ with diets at 1.5 and $0 \%$ of PF $(22.77$ vs 21.57 , 21.64 , respectively). Fatty acid profile was not different ( $p>0.05$ ) between treatments. Conclusions. Adding PF to diets for dual purpose feedlot steers does not modify animal performance, but it improves some carcass and meat characteristics. It is suggested to do more research, using the same kind of animals, but taking into consideration higher levels of PF to those used in this study, since the response could improve.

Key words: Meat, Livestock, animal feed, quality control, México. (Sources: DeCS)

\section{INTRODUCCIÓN}

La producción de carne bovina en México tiene un alto potencial, ya que existen extensas áreas para su desarrollo; sin embargo, su producción no cubre la demanda de la población nacional (1).

Este problema se agrava debido a los altos costos por concepto de alimentación, especialmente por el uso de granos como el maíz, que en la última década, su costo ha incrementado a gran escala. Por tanto, es necesario encontrar alternativas con particular énfasis en el uso eficiente de la energía, pero con menor uso de granos, a fin de incrementar la eficiencia productiva. Las grasas son una alternativa potencial, dada su alto valor energético (2). Sin embargo, las grasas como tal, tienen la desventaja de disminuir la digestibilidad de la fibra al cubrir las partículas de alimento en el rumen evitando el ataque de las bacterias (3); además inhibe la actividad fermentativa por efectos nocivos de los ácidos grasos adheridos a la pared de algunas bacterias ruminales (4). Por ello, se propone el uso de grasas protegidas, las cuales se obtienen al saponificar grasas de diferentes fuentes tanto animal como vegetal con Calcio o Magnesio y se caracterizan por ser inertes en el rumen, mantener el contenido energético, no interferir en la digestibilidad de la fibra y ser digeridas completamente en el intestino delgado (5). El uso de ellas ha sido estudiado en los últimos 20 años, básicamente en la producción de leche para incrementar el porcentaje de sólidos totales y evitar la pérdida de condición corporal (6). Su uso en producción y calidad de carne es aun limitada e inconsistente $(3,7,8)$, especialmente en países como México, donde alrededor del $50 \%$ de la carne de bovino consumida proviene de animales comerciales de la zona tropical del país, cuyo genotipo es una mezcla de razas en diversas proporciones no registradas, comúnmente llamados "de doble propósito", y después del destete, los machos son finalizados en pastoreo en la misma zona, o bien, en estabulación en zona templada (1).

Sin embargo, a pesar del aporte de carne por esta ganadería al consumo nacional, no se le ha prestado la importancia que realmente tiene, por tanto, no existen estudios, al menos no reportados, que evalúen su comportamiento productivo, especialmente lo referente a la calidad del producto. Los estudios hechos al respecto, están dirigidos a grandes explotaciones donde manejan razas puras, que después del periodo de iniciación en pastoreo, los animales son 
exportados a los Estados Unidos para su finalización y comercialización en canal y carne. Por tanto, el presente estudio tuvo como objetivo evaluar la respuesta animal y la calidad de la canal y carne a la adición de diferentes niveles de grasa protegida a dietas para toretes doble propósito, provenientes de la zona tropical de México.

\section{MATERIALES Y MÉTODOS}

Sitio de estudio. El estudio se realizó en la granja experimental de la Universidad Autónoma Chapingo, México, ubicada a $19021^{\prime}$ latitud norte y $98^{\circ}$ 53' longitud oeste, a una altitud de $2.240 \mathrm{msnm}$. El clima es templado subhúmedo con lluvias en verano, precipitación anual de $645 \mathrm{~mm}$ y temperatura media anual de $15^{\circ} \mathrm{C}(9)$.

Tratamientos. Se evaluaron tres dietas con diferentes niveles de grasa protegida (GP) de origen animal: 0, 1.5 y $3 \%$ por $\mathrm{kg}$ de alimento (MS).

Animales. Se utilizaron 45 toretes comerciales doble propósito provenientes de la zona tropical de México, cuyo genotipo corresponde a cruza Bos taurus $x$ Bos indicus en diferentes proporciones no registradas y edad promedio de 2 años. Previo al periodo experimental, el ganado fue desparasitado con ivermectina al $1 \%$ $(1 \mathrm{ml}$ por $50 \mathrm{~kg}$ de PV), vitaminado $(15 \mathrm{ml}$ de vitaminas $A, D$ y $E$ animal $\left.{ }^{-1}\right)$, vacunado (5 ml animal ${ }^{-1}$ de Ultravac $\circledR 7$ ), implantado (Zeranol, Ralgro ${ }^{\circledR}$ Mágnum) y pesado. Posteriormente se dividieron en 3 bloques de 15 toretes cada uno, de acuerdo con su peso vivo en grandes (349-390 kg), medianos (320-337 kg) y pequeños (263$318 \mathrm{~kg}$ ), para ser sacrificados a 100, 125 ó 150 días de iniciado el experimento, respectivamente, con el objetivo que todos los animales salieran con el mismo peso vivo. Dentro de cada bloque, se formaron 3 grupos de 5 animales cada uno, lo más homogéneo posible en cuanto a peso vivo, y posteriormente, cada grupo se distribuyó aleatoriamente a cada uno de los 3 tratamientos evaluados, y se alojaron en corrales individuales $(2 \times 2 \mathrm{~m}$, con fosa de recolección de heces, bebederos automáticos y comederos fijos), con 15 días de adaptación.

Manejo nutricional. La composición de las dietas experimentales elaboradas con base al NRC (2), se muestran en la tabla 1. Básicamente varió la cantidad de maíz de acuerdo al nivel de grasa protegida usada (MegaEngorda $®$ ), la cual contenía $2 \%$ de humedad, $8 \%$ de Calcio, y $88 \%$ de grasa bruta, aportando $92.5 \%$ de ácidos grasos totales (palmítico, esteárico, oleico, linoleico, linolénico, en concentraciones de 25.2, $15.7,42.2,5.3$ y $4.1 \%$, respectivamente). Los animales se alimentaron diariamente a las 7:00 y 15:00h, ofreciendo la mitad del alimento en cada ocasión.

Comportamiento animal. Consumo de materia seca (CMS), ganancia diaria de peso (GDP), conversión alimenticia (CA), grasa dorsal, peso de la canal caliente (PCC), área del ojo de la costilla (AC), y rendimiento en canal (RC).

Tabla 1. Composición de las dietas experimentales.

\begin{tabular}{lccc}
\hline & \multicolumn{3}{c}{ Grasa protegida (\%) } \\
\hline Ingredientes & $\mathbf{0}$ & $\mathbf{1 . 5}$ & $\mathbf{3 . 0}$ \\
Maíz, \% & 26.8 & 24.8 & 24.0 \\
Sorgo, \% & 19.0 & 18.5 & 18.0 \\
Barredura de pan, \% & 18.2 & 18.4 & 18.0 \\
Pasta de soya, \% & 11.4 & 11.8 & 11.4 \\
Paja de cebada, \% & 22.0 & 22.6 & 23.0 \\
Carbonato de Ca, \% & 0.3 & 0.3 & 0.3 \\
Minerales $¥$ Engorda Plus ADE), \% & 2.00 & 2.00 & 2.00 \\
Buffer †, \% & 0.3 & 0.3 & 0.3 \\
Grasa protegida (Megaengorda), \% & 0.00 & 1.50 & 3.00 \\
Composición química & & & \\
Materia Seca, \% & 91.35 & 91.65 & 91.48 \\
EN de mantenimiento, Mcal/kg & 1.74 & 1.74 & 1.74 \\
EN de ganancia, Mcal/kg & 1.11 & 1.11 & 1.11 \\
PC, \% & 13.0 & 12.9 & 12.8 \\
FDN, \% & 23.08 & 23.52 & 23.83 \\
FDA, \% & 16.5 & 16.8 & 16.8 \\
Ca, \% & 0.72 & 0.73 & 0.74 \\
P, \% & 0.32 & 0.30 & 0.29 \\
\hline
\end{tabular}

\# Ca, 19.6\%; P, 2.1\%; K, 1\%; Cl, 10\%; Mg, 0.7\%; $\mathrm{Na}, 7 \%$; S, 0.11\%; Co, 10ppm; Cu, 500ppm; I, 64ppm; Fe, 815ppm; Mn, 1280ppm; Se, 20ppm; $\mathrm{Zn}, 1800 \mathrm{ppm}$. $+\mathrm{Ca}, 9 \% ; \mathrm{Mg}, 10.8 \%$; Na, $10 \%$. EN, energía neta; PC, proteína cruda; FDN, fibra detergente neutro; FDA, fibra detergente ácido. 
El consumo de materia seca diaria se obtuvo pesando el alimento ofrecido y rechazado individualmente. La ganancia diaria de peso vivo se calculó por diferencia entre peso inicial y final dividido entre los días experimentales, y la conversión alimenticia dividiendo el consumo diario de alimento entre las ganancia diaria de peso individual. La grasa dorsal se midió entre la $12^{a}$ y $13^{a}$ costilla, un día antes del sacrificio de los animales, utilizando un ultrasonido (Sonovet 600, Universal Medical System, Inc. Transductor de 7.5 Mhz), y el área del ojo de la costilla se midió en el músculo Longissimus dorsi a nivel de la $12^{a}$ y $13^{a}$ costilla, usando una rejilla cuadriculada expresada en pulgadas y el resultado se transformó a $\mathrm{cm}^{2}$. El peso de la canal caliente se obtuvo pesando las canales postsacrificio, y el rendimiento en canal mediante la relación peso canal caliente:peso vivo.

Calidad de la carne. pH (10), actividad de agua (Aw) (10), capacidad de retención de agua (CRA) (10), humedad (HC) y proteína de la carne (PC) (11); cenizas (10) y ácidos grasos de cadena larga de carne fresca, seca y grasa subcutánea (11).

Para medir $\mathrm{pH}$, se utilizaron $10 \mathrm{~g}$ de carne molida en una licuadora con 10 $\mathrm{ml}$ de agua destilada, y la lectura se realizó introduciendo el electrodo del potenciómetro en la muestra. La actividad de agua se determinó utilizando un corte de carne de $2 \mathrm{~mm}$ de grosor, en el cual se introdujo al aparato medidor de la actividad de agua. La capacidad de retención de agua se midió utilizando $5 \mathrm{~g}$ de carne molida con $16 \mathrm{ml}$ de solución de cloruro de sodio $(\mathrm{NaCl})$ al $0.6 \mathrm{~N}$, depositados en tubos para centrífuga (JS-HS Beckman) colocados en un contenedor con hielo durante 30 minutos, para hidratar las miofibrillas. Los tubos se agitaron cada 10 minutos y se centrifugaron durante 15 minutos a 10,000 rpm. La muestra resultante se vació en una probeta. El volumen de solución que retuvo la carne fue reportado como la cantidad de agua retenida. El contenido de humedad de la carne se determinó pesando 100 $\mathrm{g}$ de carne, secada en estufa de aire a presión a $55^{\circ} \mathrm{C}$. Por diferencia de peso antes y después, se obtuvo el contenido de humedad. El contenido de proteína cruda se determinó por el método de Microkjeldahl, donde el contenido total de nitrógeno obtenido se multiplicó por el factor 6.25 (12). Los ácidos grasos se midieron por cromatografía de gases (Hewlett Packard 6890 , con inyector automático serie 7683 ) con detector de ionización de flama (FID) (10), según el método propuesto por Cañeque y Sañudo (12). La separación de los ácidos grasos se realizó utilizando una columna capilar (HP Innowax, $30 \mathrm{~m}$ $x 0.25 \mu \mathrm{m})$. Su identificación se realizó utilizando mezcla de estándares de referencia de metil esteres de ácidos grasos SUPELCO FAME (catálogo 18918-Iamp. Mix C8-C24).

Toma de muestras. Para la calidad de la carne, se tomó una muestra por animal, de aproximadamente $300 \mathrm{~g}$ de músculo Longissimus dorsi a nivel de la $12^{\mathrm{a}}$ y $13^{\mathrm{a}}$ costilla. Las muestras fueron colocadas en bolsas selladas al vacío y transportadas en hieleras al laboratorio para su análisis después de $24 \mathrm{~h}$ de escurrimiento a $-2^{\circ} \mathrm{C}$. De cada muestra, se tomaron submuestras para análisis específicos.

Análisis estadístico. Los datos obtenidos se analizaron de acuerdo a un diseño en bloques completamente al azar, con cada animal como unidad experimental. Los animales fueron agrupados en tres bloques de acuerdo con su peso vivo, dentro de cada uno, 3 grupos de 5 animales cada uno, fueron asignados aleatoriamente a cada uno de los tres niveles de grasa protegida evaluados.

El modelo fue $Y i j=\mu+T i+b j+\varepsilon i j$

Donde: Yij es la lectura del tratamiento i-ésimo en el j-ésimo bloque; $\mu$ es el promedio poblacional de la variable respuesta; Ti es el efecto del tratamiento " $i$ ", con i $=3 \mathrm{t}$; bj es el efecto del bloque ' $j$ ", con $j=3 r$; y $\varepsilon i j$ es el error asociado con la lectura del i-ésimo tratamiento en el j-ésimo bloque.

El análisis de resultados se realizó con el procedimiento GLM del programa SAS y la 
comparación de medias se realizó con la prueba de Tukey (13).

\section{RESULTADOS}

Consumo de materia (CMS), ganancia diaria de peso (GDP), conversión alimenticia (CA), peso vivo final (PVf), rendimiento de canal y peso de canal caliente, no fueron diferentes $(p>0.05)$ entre tratamientos, con promedios de 8.5 $\mathrm{kg} \mathrm{d}^{-1}, 1.3 \mathrm{~kg} \mathrm{~d}^{-1}, 6.2 \mathrm{~kg}, 491 \mathrm{~kg}, 54.3 \%$, y 267 kg, respectivamente (Tabla 2 ).

Tabla 2. Efecto de la adición de grasa protegida a dietas de toretes finalizados en corral en el comportamiento productivo e incremento de la grasa dorsal.

\begin{tabular}{lccccc}
\hline & \multicolumn{5}{c}{ \% de grasa } \\
\hline Variables & $\mathbf{0}$ & $\mathbf{1 . 5}$ & $\mathbf{3}$ & EEM & Sig. \\
CMS, kgd-1 & 7.9 & 9.0 & 8.6 & 1.29 & 0.097 \\
GDP, kgd-1 & 1.3 & 1.4 & 1.4 & 0.36 & 0.652 \\
CA, kg & 6.1 & 6.4 & 6.1 & 1.14 & 0.749 \\
PVi, kg & 321 & 320 & 326 & 21.55 & 0.424 \\
PVf, kg & 480 & 498 & 497 & 43.7 & 0.462 \\
PCC, kg & 254 & 275 & 273 & 25.8 & 0.075 \\
Rendimiento, \% & 52.9 & 55.2 & 54.9 & 3.03 & 0.087 \\
GGD, mm & $9.6^{\text {a }}$ & $9.3^{\text {sb }}$ & $8.6^{\text {b }}$ & 1.13 & 0.040 \\
\hline
\end{tabular}

abMedias con diferente literal entre columnas son diferentes $(p<0.05)$. CMS, consumo de materia seca; GDP, ganancia diaria de peso; $C A$, conversión alimenticia; PVi, peso vivo inicial; PVf, peso vivo final; PCC, peso de la canal caliente; GGD, grosor de grasa dorsal; EEM, error estándar de la media.

Hubo diferencias $(p<0.05)$ entre tratamientos para la variable grosor de grasa dorsal (GGD), donde animales no suplementados con GP presentaron mayores valores, seguidos de aquéllos suplementados con 1.5 y $3 \%$ de GP, respectivamente (Tabla 2 ).

No hubo diferencias $(p>0.05)$ en el área del ojo de la costilla (AC), pH, actividad de agua (Aw), capacidad de retención de agua (CRA), humedad y cenizas; sin embargo, sí hubo $(p<0.05)$ en contenido de proteína, siendo mayor en animales que consumieron alimento con $3 \%$ de GP, comparado con aquéllos que consumieron dieta con 0 y 1.5 GP (Tabla 3).
Tabla 3. Efecto de la adición de grasa protegida a dietas de toretes finalizados en corral en las características y composición química de la carne.

\begin{tabular}{lccccc}
\hline \multicolumn{7}{c}{ Grasa protegida (\%) } \\
\hline Variables & $\mathbf{0}$ & $\mathbf{1 . 5}$ & $\mathbf{3}$ & $\mathrm{EEM}$ & Sig. \\
$\mathrm{AC}, \mathrm{cm}^{2}$ & 88.2 & 86.4 & 94.9 & 14.22 & 0.258 \\
$\mathrm{pH}$ & 5.5 & 5.5 & 5.5 & 0.28 & 0.807 \\
$\mathrm{AW}$ & 0.95 & 0.96 & 0.96 & 0.006 & 0.199 \\
$\mathrm{CRA}, \mathrm{mL}$ & 31.33 & 39.14 & 34.26 & 11.691 & 0.308 \\
Humedad, \% & 72 & 72 & 71 & 1.133 & 0.197 \\
Proteína, \% & $21.64^{\mathrm{b}}$ & $21.57^{\mathrm{b}}$ & $22.77^{\mathrm{a}}$ & 1.129 & 0.016 \\
Cenizas, \% & 1.04 & 1.04 & 1.05 & 0.023 & 0.188 \\
\hline
\end{tabular}

abMedias con diferente literal entre columnas son diferentes $(p<0.05)$. AC, área del ojo de la costilla; $A w$, actividad de agua; CRA, capacidad de retención de agua; EEM, error estándar de la media.

El contenido de ácidos grasos en carne fresca y seca, así como en grasa de cobertura, tampoco fue diferente $(p>0.05)$ entre tratamientos (Tabla 4).

Tabla 4. Perfil de ácidos grasos de carne fresca y seca del músculo Longissimus dorsi, y grasa subcutánea de toretes alimentados con dietas con diferentes niveles de grasa protegida.

\begin{tabular}{|c|c|c|c|c|c|c|}
\hline \multirow{3}{*}{\multicolumn{2}{|c|}{$\begin{array}{l}\text { Ácidos Grasos, } \% \\
\text { Carne fresca }\end{array}$}} & \multicolumn{5}{|c|}{ Grasa protegida (\%) } \\
\hline & & \multirow{2}{*}{0} & \multirow[t]{2}{*}{1.5} & \multirow[t]{2}{*}{3} & \multirow[t]{2}{*}{ EEM } & \multirow[t]{2}{*}{ Sig. } \\
\hline & & & & & & \\
\hline Mirístico & C14:0 & 2.2 & 2.3 & 2.5 & 0.94 & 0.271 \\
\hline Imít & $\mathrm{C} 16: 0$ & 23.0 & & & 1.92 & 0.128 \\
\hline mito & $\mathrm{C} 16: 1$ & 2.2 & & & 0.91 & 0.242 \\
\hline teári & C18:0 & 28.7 & & & 5.83 & 0.520 \\
\hline eico & C18:1 & 31.0 & & & 4.86 & 0.624 \\
\hline Ioleico & $18: 2$ & 7.2 & & & 2.28 & 0.315 \\
\hline inolénico & & 6.3 & & & 2.21 & 0.562 \\
\hline \multicolumn{7}{|c|}{ Carne seca } \\
\hline Mirístico & C14:0 & 2.7 & & & 0.54 & 0.443 \\
\hline Imíti & $\mathrm{C} 16: 0$ & 27.5 & 28. & 28.5 & 1.75 & 0.207 \\
\hline mit & $\mathrm{C} 16: 1$ & 3.1 & & & 0.49 & 0.332 \\
\hline teár & $\mathrm{C} 18: 0$ & 21.1 & 20 & & 2.35 & 0.083 \\
\hline eico & C18:1 & 37.4 & 37.3 & & 2.24 & 0.736 \\
\hline Ioleic & C18:2 & 6.3 & & & 1.36 & 0.234 \\
\hline Linolénico & $\mathrm{C} 18: 3$ & 2.2 & & & 0.87 & 0.209 \\
\hline \multicolumn{7}{|c|}{ Grasa subcutánea } \\
\hline lirístico & C14:0 & 3.4 & & & 0.565 & 0.466 \\
\hline Imít & $\mathrm{C} 16: 0$ & 26.3 & & 25.8 & 1.002 & 0.534 \\
\hline mitc & $\mathrm{C} 16: 1$ & 5.2 & & & 1.734 & 0.284 \\
\hline steárico & C18:0 & 15.2 & & 13.1 & 4.024 & 0.488 \\
\hline leico & C18:1 & 47.0 & 47.3 & 48.8 & 2.976 & 0.561 \\
\hline noleico & C18:2 & 1.9 & 2.1 & 2.1 & 0.333 & 0.443 \\
\hline nolénico & C18:3 & 0.4 & 0.6 & 0.4 & 0.206 & 0.482 \\
\hline
\end{tabular}




\section{DISCUSIÓN}

Consumo de alimento. Adicionar grasa protegida a la dieta de los toretes, no afectó significativamente el consumo de materia seca (CMS), resultado que coincide con lo reportado por Nelson et al (14). Sin embargo, Feton y Kerley (15) y Fernandes et al (16), reportan que a mayor adición de grasa en la dieta disminuye el CMS, debido a una menor digestibilidad del alimento, ya que interfiere con la acción de las bacterias en el rumen al momento de degradar la fibra, disminuyendo la palatabilidad e incrementando los problemas de acidosis (17). LaBrune et al (18) reportaron que adicionar grasa a la dieta de razas especializadas en producción de carne, la disminución del consumo de materia seca se debe a que se cubren más rápidamente los requerimientos de energía. Otros reportes sugieren que al adicionar grasa a dietas a base de maíz, se incrementa el contenido de energía de la dieta, con la consecuente disminución del consumo de materia seca (19). Sin embargo, estas diferencias no se apreciaron en los resultados de nuestro experimento, debido probablemente a la combinación de sorgo-maíz utilizada en la dieta testigo, que atenuó la diferencia en CMS entre tratamientos.

\section{Comportamiento productivo. EI} comportamiento productivo de los animales experimentales no se vio afectado por adicionar GP a su dieta. Similares resultados reportaron Montgomery et al (20) al adicionar diferentes fuentes de grasa en la dieta. Contrariamente, LaBrune et al (18) reportaron que adicionar $4 \%$ de cebo a la dieta de razas especializadas en producción de carne, mejoró las ganancias diarias de peso, con mejorías en la eficiencia alimenticia. Esto sugiere que es posible que incrementar el nivel de GP en la dieta, la respuesta animal podría mejorar.

El grosor de grasa dorsal que fue menor en animales alimentados con 3\% de GP (Tabla 2 ), se atribuye a que disminuyó el valor energético de la dieta al incrementar los niveles de grasa, ya que a mayor contenido de grasa en una dieta, la digestibilidad de los ácidos grasos es menor $y$, por tanto, disminuye la deposición de grasa de cobertura. Esto indica que dietas con alto porcentaje de grano contienen gran cantidad de carbohidratos, los cuales, al no ser utilizados completamente, se almacenan en forma de grasa de cobertura (21). Estos resultados contradicen lo reportado por LaBrune et al (18) y Nelson et al (4), quienes encontraron mayor deposición de grasa conforme se incrementa la adición de grasa a la dieta.

Calidad de la carne. El no haber encontrado diferencias significativas en área del ojo de la costilla (AC) entre tratamientos (Tabla 3), coincide con lo reportado por Nelson et al (4), quienes tampoco encontraron diferencias en $A C$, $y$ aunque utilizaron diferente fuente $y$ cantidad de grasa en la dieta, sugieren que el uso de grasa en alimentación animal, no afecta AC.

El incremento en el contenido de proteína de la carne con la adición de GP, es resultado de una mejor relación proteína digestible/energía digestible (11), en la que una sincronización energía:proteína en tiempo y forma, mejora la eficiencia y cantidad de proteína microbiana.

Los valores de $\mathrm{pH}$ de la carne encontrados en este experimento fueron normales para la carne de bovinos (Tabla 3) y no fue afectado por la adición de grasa protegida a la dieta. El rango reportado oscila entre 5.4 y 5.8 , dentro del cual se realiza un metabolismo posmortem normal e indica menor estrés premortem de los animales, pudiendo obtener carne con buenas características organolépticas (22).

La CRA no fue afectada por la adición de grasa a las dietas en este experimento, a pesar que se ha reportado que animales que han recibido una dieta con alto valor energético, presentan mayores valores de CRA (14). Esto indica que el CRA podría incrementar si se elevara la cantidad de GP en la dieta.

Del total de ácidos grasos reportados en este experimento, aproximadamente $52 \%$ correspondió a ácidos grasos 
saturados, mientras que el $48 \%$ restante fueron insaturados. Los ácidos grasos monoinsaturados varían en cantidad dependiendo de la carne, ya que en la carne fresca se obtuvo $34.5 \%$, mientras que en la carne seca se incrementó a $40.7 \%$. Caso contrario se presenta en el total de los ácidos grasos poliinsaturados. Mientras que en la carne fresca fue $12.8 \%$, en la carne seca disminuyó a $9.0 \%$. Esta disminución se presentó debido a que se pierde grasa de la carne en el proceso de molienda, afectando los ácidos grasos que se encuentran en bajas cantidades, entre ellos, el ácido linolénico. Del perfil total de ácidos grasos reportados en este estudio, aproximadamente $83.5 \%$ es aportado por los ácidos grasos palmítico, esteárico y oleico, en tanto que mirístico, palmitoleico, linoleico y linolénico aportan el $16.5 \%$ restante.

Felton y Kerley (15) encontraron en grasa subcutánea y carne magra, incrementos de los ácidos grasos poli-insaturados cuando incluyeron granos enteros de soya en la dieta de becerros. Explicaron que la combinación del ambiente ruminal para saturar los ácidos grasos insaturados disponibles en el rumen, permitieron dejar intacta las semillas de soya, no rompiendo su cubierta, y por tanto, protegiendo su elevado contenido de ácidos grasos insaturados que pasaron a tracto posterior. Dicho estudio confirma que el uso de grasas protegidas con alto contenido de ácidos grasos poliinsaturados puede incrementar el contenido de ácidos grasos esenciales en la carne de bovinos. Sin embargo, en este experimento no se observó este efecto, a pesar que la GP utilizada contenía alta concentración de ácidos grasos poliinsaturados. Es posible que el aporte de lípidos a través del maíz y barredura de pan en las dietas experimentales, contrarrestó este efecto (3).

La mayor concentración de ácidos grasos correspondió al oleico, en todos los tratamientos, independientemente del estado físico de la carne. Esto concuerda con lo reportado por otros autores $(15,23)$, y se debe a la baja tasa de biohidrogenación (24), sin efecto por el nivel de ácidos grasos consumidos por el animal $(17,25)$, a pesar que la GP utilizada en este experimento contenía un elevado porcentaje de ácido oleico. A este respecto, ha sido reportado que cuantificar los ácidos grasos que realmente pasan a duodeno para su absorción y transferidos a carne y/o leche, es crítico, dado que los lípidos de la dieta transformados en rumen (alrededor de 60\%) y los sintetizados por los microorganismos ruminales (alrededor de 35\%), constituyen el 95\% de los lípidos totales que llegan al rumen (3). Esto sugiere que determinado porcentaje del ácido oleico, dado que es un ácido graso no esencial, fue producido vía endógena, incrementando así su concentración.

Los ácidos grasos linoleico y linolénico constituyeron un $6.4 \%$ en la carne fresca, mientras que en carne seca sólo se encontraron en $4.5 \%$. Estos resultados difieren de los reportados por LaBrune et al (18) y Hutchison et al (26). Además, el perfil de ácidos grasos es consecuencia también del efecto genotipo (27). Desafortunadamente no fue posible corroborarlo en este estudio dado que no se obtuvo información de las proporciones genotípicas de los animales experimentales, situación común en los sistemas de producción de doble propósito del trópico mexicano, donde no se llevan registros genéticos, aún cuando representan un alto porcentaje a la producción de carne a nivel nacional. Por ello la importancia y necesidad de evaluar este tipo de animales, y es en absoluto, objetivo de nuestro grupo de investigadores seguir estudiándolos, con el compromiso de considerar en todo lo posible el factor genética.

El contenido de ácidos grasos de cadena larga de la grasa subcutánea no fue diferente $(p>0.05)$ entre tratamientos. Hubo cambios marcados entre los ácidos grasos mirístico, palmítico, palmitoleico y esteárico entre la carne y la grasa. Es interesante observar que el ácido oleico fue mayor y el linoleico y linolénico menor en la grasa subcutánea comparado con lo encontrado en carne. La importancia de incrementar la concentración de ácidos grasos esenciales en la carne para consumo 
humano, radica en el incremento de riesgos de enfermedades a causa de las grasas saturadas, principalmente enfermedades cardiovasculares como arteriosclerosis y la formación de coágulos $(17,28)$.

En las condiciones en que se desarrolló el experimento, y al tipo de animales utilizados, incluir grasa protegida en la dieta, no presentó beneficios significativos en comportamiento productivo, pero mejoró la calidad de la canal al reducir la cantidad de grasa dorsal depositada, e incrementó el contenido de proteína de la carne, aunque no afectó el perfil de ácidos grasos. Es posible que el uso de mayores niveles y otras fuentes de grasa protegida en la dieta, pudiera mejorar los parámetros de calidad de la canal y carne, sin afectar el desempeño productivo. Por lo que se sugiere realizar mayor investigación al respecto, considerando el tipo de animales usados en esta investigación, ya que son de gran importancia en la ganadería nacional.

\section{Agradecimientos}

Agradecemos al Consejo Nacional de Ciencia y Tecnología (CONACyT)-México por la beca otorgada para realizar los estudios de Maestría del primer autor, y a la Universidad Autónoma ChapingoMéxico, a través del Módulo de Producción de Carne y Patronato Universitario, por el apoyo brindado para la realización de esta investigación.

\section{REFERENCIAS}

1. Secretaría de Agricultura, Ganadería, Desarrollo Rural, Pesca y Alimentación. 2006 (fecha de acceso 11 de junio de 2007); número 153/06. México DF. Disponible en www.sagarpa.gob.mx

2. National Research Council. Nutrient Requirements of Beef Cattle. 7a ed. Washinton D.C. USA. 2000.

3. Hess BW, Moss GE, Rule DC. A decade of developments in the area of fat supplementation research with beef cattle and sheep. J Anim Sci 2008; 86:E188-E204.

4. Nelson ML, Marks DJ, Busboom JR, Cronrath JD, Falen L. Effects of supplemental fat on growth performance and quality of beef from steers fed barley-potato product finishing diets: I. Feedlot performance, carcass traits, appearance, water binding, retail storage, and palatability attributes. J Anim Sci 2004; 82:3600-3610.

5. Plascencia JA, Mendoza MGD, Vásquez PC, Zinn RA. Factores que influyen en el valor nutricional de las grasas utilizadas en las dietas para bovinos de engorda en confinamiento: una revisión. Interciencia 2005; 30(3): 134-142.
6. González F, Bas F. Efecto de la suplementación con un aceite hidrogenado de pescado sobre la producción de leche en vacas Holstein Friesian. Cien Inv Agr 2002; 29:73-82.

7. Wistuba TJ, Kegley EB, Apple JK. Influence of fish oil in finishing diets on growth performance, carcass characteristics, and sensory evaluation of cattle. J Anim Sci 2006; 84:902-909.

8. Plascencia A, Zinn RA. Comparative feeding value of tallow vs. yellow grease in finishing diets for feedlot cattle. Proc West Sec Am Soc Anim Sci 2001; 52: 566-568.

9. García E. Modificaciones al Sistema de Clasificación Climática Köpen para adaptarlo a las condiciones de la República Mexicana. $4^{a}$ ed. México, D.F. UNAM. 1987.

10. Nielsen S. Food analysis. 3rd ed. New York. Academic/Plenum Publishers. 2003. 
11. Oliván M, Mocha M, Martínez MJ, García MJ, Noval G, Osorio K. Análisis químico de la carne. En: Cañeque $V$, Sañudo C. Metodología para el estudio de la calidad de la canal y de la carne en rumiantes. Madrid, España: Instituto Nacional de investigación y Tecnología Agraria y Alimentaria. Ministerio de Ciencia y Tecnología. 2000.

12. Cañeque V, Sañudo C. Metodología para el estudio de la calidad de la canal y de la carne en rumiantes. Madrid, España. Instituto Nacional de investigación y Tecnología Agraria y Alimentaria. Ministerio de Ciencia y Tecnología. 2000.

13. Steel RGD, Torrie JH. Principles and Procedures of Statistics. New York, NY: McGraw Hill Book Co. Inc;1992.

14. Nelson L, Busboom JR, Ross CF, O'Fallon JV. Effects of supplemental fat on growth performance and quality of beef from steers fed corn finishing diets. J Anim Sci 2008; 86:936-948.

15. Felton EED, Kerley MS. Performance ans carcass quality of steers fed different sources of dietary fat. J Anim Sci 2004; 82:1794-1805.

16. Fernandes AR. Chemical traits and fatty acids composition of beef from young bulls, steers and heifers fed corn silage and concentrate or sugarcane and concentrate with sunflower grain. R Bras Zootec 2009; 38:705-712.

17. Jenkins TC, Wallace RJ, Moate $P J$, Mosley EE. BOARD-INVITED REVIEW: Recent advances in biohydrogenation of unsaturated fatty acids within the rumen microbial ecosystem J Anim Sci 2008; 86:397-412.

18. LaBrune $H J$, Reinhardt CD, Dikeman $M E$, Drouillard JS. Effects of grain processing and dietary lipid source on performance, carcass characteristics, plasma fatty acids, and sensory properties of steaks from finishing cattle. J Anim Sci 2008; 86:167-172.
19. Esterhuizen J, Gruenewald IB, Strydom PE, Hugo A. Theperoformance and meat quality of Bonsmara steers raised in al feedlot on conventional pastures or on organic pastures. SA J Anim Sci 2008; 38:303.

20. Montgomery SP, Drouillard JS, Sindt JJ, Greenquist MA, Depenbusch BE, Good EJ, Loe ER, Sulpizio MJ, Kessen TJ, Ethington RT. Effects of dried full-fat corn germ and vitamin $E$ on growth performance and carcass characteristics of fininishing cattle. J Anim Sci 2005; 83:2440-2447.

21. Montgomery SP, Drouillard JS, Nagaraja TG, Titgemeyer EC, Sindt J]. Effects of supplemental fat source on nutrient digestion and ruminal fermentation in steers. J Anim Sci 2008; 86:640-650.

22. Ciria JB, Asenjo. Factores a considerar en el presacrificio y postsacrificio. En: Cañeque V, Sañudo C. Metodología para el estudio de la calidad de la canal y de la carne en rumiantes. Madrid, España: Instituto Nacional de investigación y Tecnología Agraria y Alimentaria. Ministerio de Ciencia y Tecnología; 2000.

23. Prado IN, Moreira FB, Matsushita M. Longissimus dorsi fatty acids composition of Bos indicus and Bos indicus $x$ Bos Taurus crossbed steers finished in pasture. Braz Arch Bio Technol 2003; 46(4):601-608.

24. Lee MRF, Tweed JKS, Moloney AP, Scollan ND. The effects of fish oil supplementation on rumen metabolism and the biohydrogenation of unsaturated fatty acids in beef steers given diets containing sunflower oil. J Anim Sci 2005; 80:361-367.

25. Duckett SK, Andrea JG, Owens FN. Effect of high-oil corn or added corn oil on ruminal biohydrogenation of fatty acids and conjugated linoleic acid formation in beef steers fed finishing diets. J Anim Sci 2002; 80:3353-3360. 
26. Hutchison S, Kegley EB, Apple JK, Wistuba TJ, Dikeman ME, Rule DC. Effects of adding poultry fat in the finishing diet of steers on performance, carcass characteristics, sensory traits ans fatty acid profiles. J Anim Sci 2006; 84:2426-2435.

27. López-Trujillo R, García-Elizondo $R$, Mellado-Bosque M, Acosta-Ortiz J. Crecimiento y características de la canal de bovinos Charolais y Beefmaster alimentados con dos fuentes de proteína y dos niveles de grasa sobrepasante. Tec Pecu Mex 2002; 40(3):291-298.
28. Whetsell MS, Rayburn EB, Lozier JD. Human health effects of fatty acids in beef. Pasture-based beef systems for Appalachia. West Virginia University: Extension service; 2003. 